\title{
Characteristics of beach profiles and bar formation changes along the coasts of Hokkaido
}

\author{
H. Gotoh ${ }^{1}$, M. Takezawa ${ }^{1} \& \mathrm{~S}$. Tomaki ${ }^{2}$ \\ ${ }^{I}$ Department of Civil Engineering, College of Science and Technology, \\ Nihon University, Japan \\ ${ }^{2}$ Kumashiro System Frontier Co. Ltd., Japan
}

\begin{abstract}
This study presents the characteristics of cross-sectional beach topographical features facing the Pacific Ocean, the Japan Sea, and the Ohotsuku Sea around the island of Hokkaido, Japan.

Generally, given the numerous phenomena affecting both alongshore and offshore sediment transport, it is difficult to systematically characterize changes in the topography of coastal features. Nonetheless, the construction of maritime structures requires that a method for expressing complex beach topographies be developed. It is therefore necessary to develop an integrated quantitative methodology to characterize coastal topography.

In this study, we have attempted to clarify the cross-sectional topographic characteristics of beaches using survey data. In addition, differences in the characteristics of the coastlines facing the Pacific Ocean, the Japan Sea, and the Ohotsuku Sea in Hokkaido are presented, and an attempt is made to express complex beach topography using fractals. The values calculated for the fractal dimension provide evidence for the existence of self-similarity among the beach topographies examined.

Keywords: cross-sectional beach topography, bar, stable point, self-similarity, fractal dimension.
\end{abstract}

\section{Introduction}

The island of Hokkaido is surrounded by the Pacific Ocean, the Japan Sea, and the Ohotsuku Sea (Figure 1). The coastline of Hokkaido is approximately 2767 


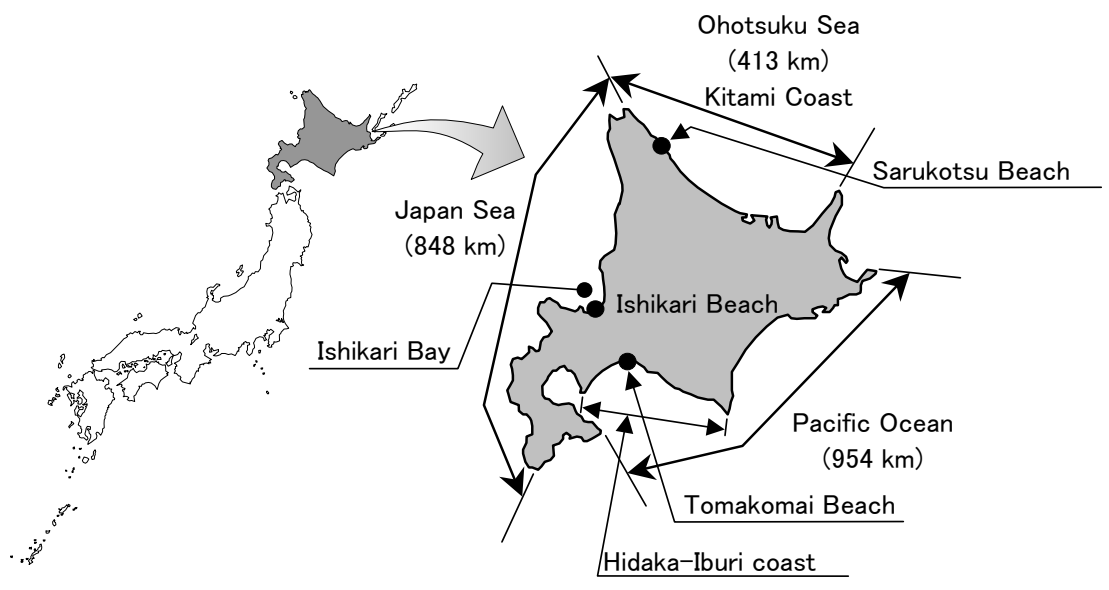

Figure 1: $\quad$ Study area (Hokkaido).

$\mathrm{km}$, and the beach topography features of the island have several unique meteorological and maritime characteristics.

In this study, we surveyed the topography of Ishikari Beach, which faces the Japan Sea, Tomakomai Beach, which faces the Pacific Ocean, and Sarukotsu Beach, which faces the Ohotsuku Sea. Using the results of the surveys, we then attempted to characterize the topographical features of several beaches along these coastlines. Given the marked complexity of these features, an attempt was made to express this complexity in the fractal dimension. The fractal dimension calculations for the beaches show evidence of self-similarity among these topographical features. We found that the fractal dimensions of beach topographical features were 1.08 1.15 along the Hokkaido coast.

\section{Description of Ishikari, Tomakomai, and Sarukotsu Beaches}

We conducted extensive surveys of several beaches around Hokkaido and the summarized the data in Table 1. A description of every beach is as follows:

\subsection{Ishikari Beach}

Ishikari Beach is located on the inside of Ishikari Bay (Figure 1). A new harbor was constructed in the bay in 1973 and we have conducted surveys on the beach every summer and winter since then. After construction of the harbor, the beach to the southern side of the harbor tended to become eroded by wave action and altered flow. Conversely, the beach on the northern side of harbor was characterized by the deposition of sediment. 
Table 1: $\quad$ Summary of survey.

\begin{tabular}{|c|c|c|c|c|}
\hline Beach name & Transect & Times of survey & Date & $\begin{array}{l}\text { Period of observation on } \\
\text { waves toward beach, } \\
\text { Number of samples (n) }\end{array}$ \\
\hline $\begin{array}{c}\text { Ishikari } \\
\text { (North side) }\end{array}$ & 3150 m & $\begin{array}{c}72 \text { cases } \\
\text { (6 survey lines: } \\
\text { separations of } 200 \text { - } \\
1200 \text { m between } \\
\text { each survey line) }\end{array}$ & \multirow{2}{*}{$\begin{array}{l}\text { 1984-1991 } \\
\text { (July, August, and } \\
\text { December) }\end{array}$} & \multirow{2}{*}{$\begin{array}{c}1972 \\
\text { (January } \\
\cdot \\
\text { December) } \\
n=106\end{array}$} \\
\hline $\begin{array}{c}\text { Ishikari } \\
\text { (South side) }\end{array}$ & $3550 \mathrm{~m}$ & $\begin{array}{c}80 \text { cases } \\
\text { (6 survey lines: } \\
\text { separations of } 400 \text { - } \\
1200 \text { m between } \\
\text { survey line) }\end{array}$ & & \\
\hline Tomakomai & $20000 \mathrm{~m}$ & $\begin{array}{c}95 \text { cases } \\
\text { (19 survey lines: } \\
\text { separations of } 1000 \\
\text { m between survey } \\
\text { line) }\end{array}$ & $\begin{array}{c}1972 \\
\text { (March and } \\
\text { August), } \\
1973 \\
\text { (February, August, } \\
\text { and December) }\end{array}$ & $\begin{array}{c}1972 \\
\text { (January } \\
\cdot \\
\text { December) } \\
\mathrm{n}=105\end{array}$ \\
\hline Sarukotsu & $2000 \mathrm{~m}$ & $\begin{array}{c}84 \text { cases } \\
\text { (21 survey lines: } \\
\text { separations of } 1000 \\
\text { m between survey } \\
\text { line) }\end{array}$ & $\begin{array}{c}1974 \\
\text { (August), } 1975 \\
\text { (June, July, and } \\
\text { November) }\end{array}$ & $\begin{array}{c}1975 \\
\text { (May } \\
\cdot \\
\text { December) } \\
\mathrm{n}=115\end{array}$ \\
\hline
\end{tabular}

\subsection{Tomakomai Beach}

Tomakomai Beach is located along the Hidaka-Iburi coastline (Figure 1). It is also the site where a new large harbor is to be constructed and, consequently, we have extended the width of the survey region to exceed $20 \mathrm{~km}$. Since the construction of the new harbor had not yet start when we initially surveyed the beach, there were no the artificial structures at the beach.

\subsection{Sarukotsu Beach}

As shown in Figure 1, Sarukotsu Beach is located along the northern Kitami coast. Ice is often seen in winter and instances of ice washing up on the beach have been observed in the past. 


\section{Relationship between wave conditions and littoral drift}

We examined littoral drift on the every beach using the relationship between wave height, wave period and the median diameter of sand particles.

Horikawa et al. [1] proposed a method for classifying beach topography using a function of seafloor slope, sand particle diameter, wave height, and wavelength.

Shibayama and Horikawa [2] also characterized littoral drift using Shields number $\varphi_{\mathrm{m}}$ and the ratio of the sedimentation velocity $\omega_{0}$ to the horizontal velocity at the seafloor $u_{b}$. We used this method for the beaches in this study.

The data for wave height and period, $\varphi_{\mathrm{m}}$ and $u_{b} / \omega_{0}$, for every beach in our study were plotted as shown in Figure 2. For purposes of calculation, median sand diameter was assumed to be $0.15 \mathrm{~mm}$ (Ishikari), $0.38 \mathrm{~mm}$ (Tomakomai), and $0.20 \mathrm{~mm}$ (Sarukotsu) based on the extraction of sand at the extrapolation of sand-grain size in the surf zone. Also, the value employed for the friction factor $f_{\omega}$ was 0.015 , which is generally accepted as being suitable [3]. Also, the wave data shown in Table 2 was used and waves were defined as "High", "Medium", and "Small" (see Table 2) in order to calculate $\varphi_{\mathrm{m}}$ and $u_{b} / \omega_{0}$.

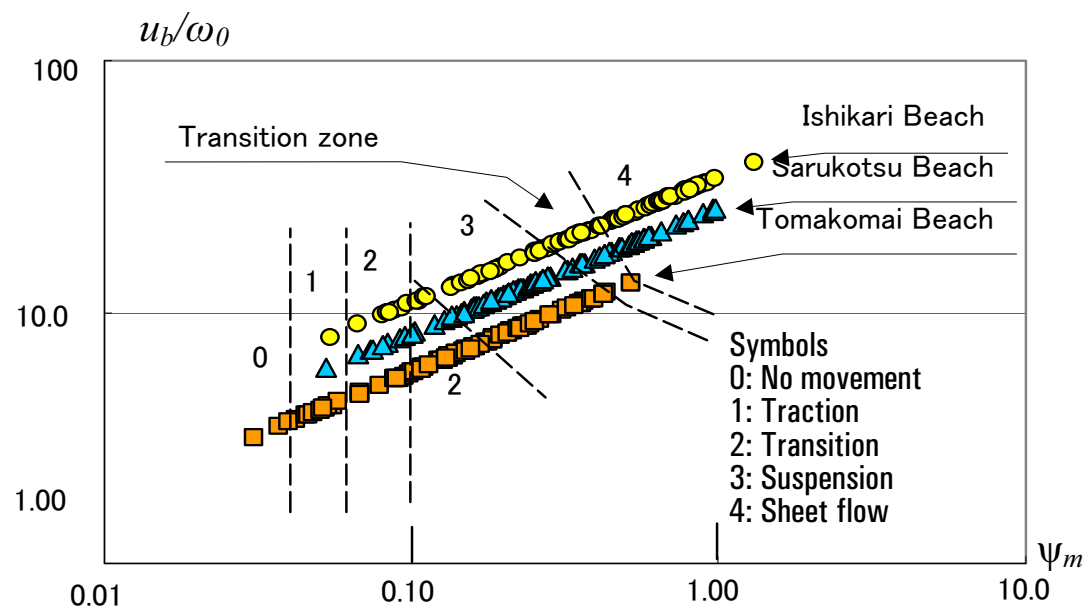

Figure 2: Classification of littoral drift along the beaches examined.

Table 2: $\quad$ Classification of wave height $(\mathrm{m})$ and wave period (s).

\begin{tabular}{|c|c|c|c|}
\hline Class & $\begin{array}{c}\text { Ishikari } \\
\text { Beach }\end{array}$ & $\begin{array}{c}\text { Tomakomai } \\
\text { Beach }\end{array}$ & $\begin{array}{c}\text { Sarukotsu } \\
\text { Beach }\end{array}$ \\
\hline \hline High & $7.7 \mathrm{~m}(0.11 \mathrm{~Hz})$ & $6.1 \mathrm{~m}(0.065 \mathrm{~Hz})$ & $7.3 \mathrm{~m}(0.078 \mathrm{~Hz})$ \\
waves & $\sim 4.0 \mathrm{~m}(0.15 \mathrm{~Hz})$ & $\sim 4.0 \mathrm{~m}(0.072 \mathrm{~Hz})$ & $\sim 4.4 \mathrm{~m}(0.10 \mathrm{~Hz})$ \\
\hline Medium & $4.0 \mathrm{~m}(0.19 \mathrm{~Hz})$ & $3.9 \mathrm{~m}(0.12 \mathrm{~Hz})$ & $4.3 \mathrm{~m}(0.094 \mathrm{~Hz})$ \\
waves & $\sim 2.3 \mathrm{~m}(0.16 \mathrm{~Hz})$ & $\sim 2.1 \mathrm{~m}(0.15 \mathrm{~Hz})$ & $\sim 2.3 \mathrm{~m}(0.11 \mathrm{~Hz})$ \\
\hline Small & $2.2 \mathrm{~m}(0.16 \mathrm{~Hz})$ & $2.0 \mathrm{~m}(0.16 \mathrm{~Hz})$ & $2.2 \mathrm{~m}(0.11 \mathrm{~Hz})$ \\
waves & $\sim 0.3 \mathrm{~m}(0.18 \mathrm{~Hz})$ & $\sim 0.2 \mathrm{~m}(0.11 \mathrm{~Hz})$ & $\sim 0.3 \mathrm{~m}(0.16 \mathrm{~Hz})$ \\
\hline
\end{tabular}


As shown in Figure 2, classification of littoral drift at the different beaches differed markedly due to different wave characteristics at every beach. Interestingly, sheet flow did not exist at Tomakomai Beach. Conversely, for Ishikari and Sarukotsu beaches, littoral drift has been occurred by sheet flow, suspension, and traction.

As mentioned above, these differences in littoral drift between beaches are likely to reflect differences in the cross sectional topography of the coast at these locations.

\section{Results of the survey}

Figure 3 shows the different cross sectional topographies of the beaches that we surveyed. As shown in Figure 3, several differences could be observed in the characteristics of the beaches.

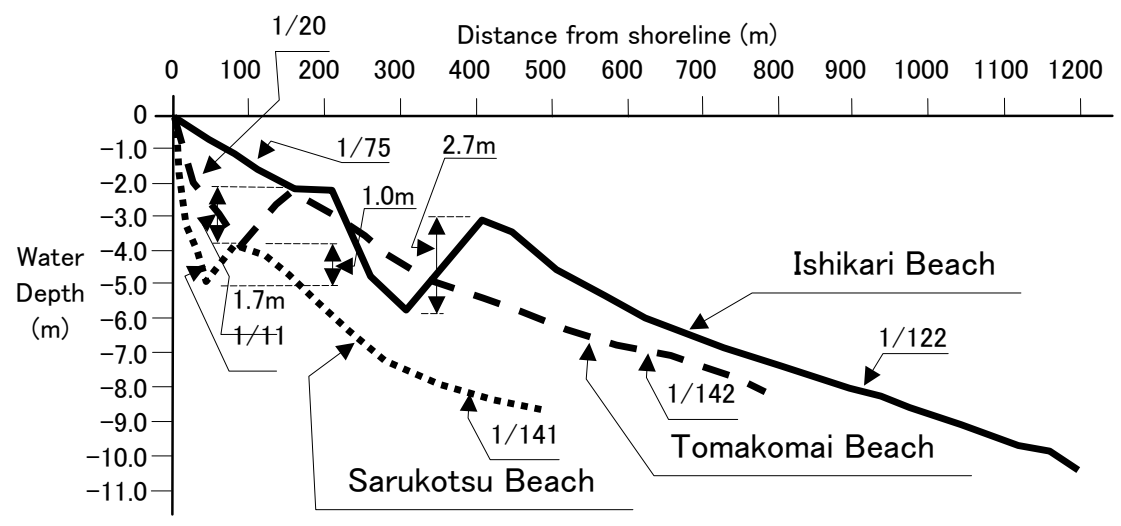

Figure 3: Typical cross sectional topography of the respective beaches.

First, a difference in the depth between the trough and the bar crest of every coast could be observed. For example, in the case of Ishikari beach, the magnitude of this difference is approximately $2.7 \mathrm{~m}$. For Tomakomai Beach, the magnitude is approximately $1.7 \mathrm{~m}$, and for Sarukotsu Beach it is approximately $1.0 \mathrm{~m}$. Movement in the position of the bar was most stable at Sarukotsu Beach compared with bars at Ishikari and Tomakomai beaches.

Second, differences in the foreshore slopes of Ishikari, Tomakomai, and Sarukotsu beaches were observed, with magnitudes of $1 / 75,1 / 20$, and 1/11, respectively. These differences were thought to be due to the disparities in wave action acting on the beach. In addition, for Sarukotsu Beach, as the drift ice erodes the beach, the gradient of the foreshore was observed to increase.

Third, the magnitude of the offshore slopes from the bar for Ishikari, Tomakomai, and Sarukotsu beaches is $1 / 122,1 / 142$, and 1/141, respectively; the magnitudes of the offshore slopes are thus less than those of the foreshore slopes for these beaches. 


\section{Fractal dimension on cross sectional topography of beaches}

Fractal dimension were first to apply to the analysis of Lewis Fry Richardson [4]. We proposed that a general expression describing the cross sectional topography of beach could be obtained using fractal.

In order to calculate the fractal dimension, we have to define the cross sectional topography of beach. As shown in Figure 4, we defined the cross sectional topography of the beach as the shade area AFCDE. Here, point " $C$ " is the "Stable Point" which is defined as the point at which a remarkable change of topography is not recognized [5], point " $\mathrm{A}$ " is the position of shoreline at low tide, point " $G$ " is the position of seafloor at the horizontal distance of $20 \mathrm{~m}$ from the shoreline, and point " $G$ " is the crest of bar. And also, $\alpha$ is the angle of average bed slope from point " $A$ " to point " $G$ ", $\beta$ is the slope from point " $A$ " to point " $F$ ", and $\theta$ is the slope from point " $F$ " to point " $C$ ".

The shade area "S" and the circumference "L" of AFCDE for Ishikari (152 cross sections), Tomakomai (95 cross sections), and Sarukotsu (84 cross sections) beaches based on the survey is shown in Figure 5. Interestingly, the same trend is observed along all of the coasts. The fractal dimensions for the different beaches were 1.152, 1.080, and 1.110, for Ishikari, Tomakomai, and Sarukotsu Beaches as shown in Table 3. It was clarified that the cross sectional topography of Ishikari Beach was more complex than those of Tomakomai and Sarukotsu beaches. In addition, the area to the south of Ishikari Beach has experienced erosion since the construction of the new Ishikari harbor, while the area to the north has experienced marked deposition of sediment. Given that the fractal dimension values for the north and the south beaches are very close to each other, it appears that a condition of self-similarity has been obtained. If the conditions affecting the waves that approach the beach are the same, then it is likely that the same fractal dimension values can be obtained.

\section{Relationship between seafloor slope and cross-sectional coastal topography}

\subsection{Effect of bar position on fractal dimension}

We attempted to investigate the effect of bar position on fractal dimension. Here, the seafloor slope is defined as the slope at the Stable Point "C" as shown in

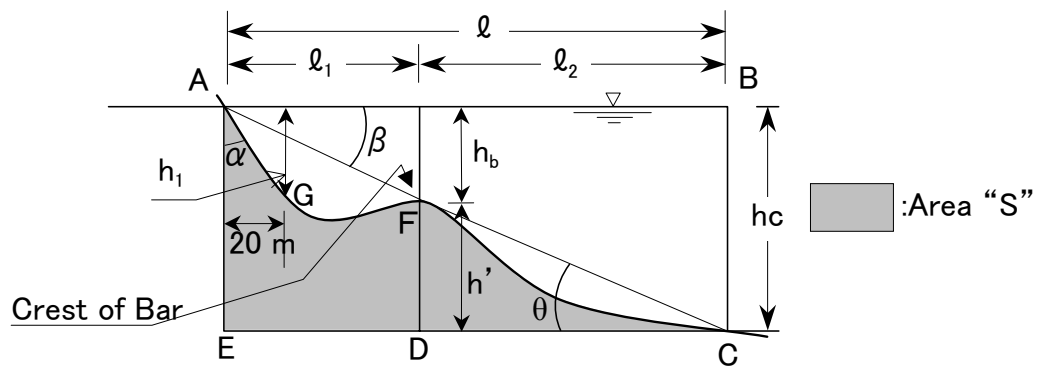

(Stable Point)

Figure 4: $\quad$ Sketch showing cross-sectional beach topography. 
Figure 4 [5]. This is useful examination for understanding the changes in the cross-sectional topography of a beach.

In order to evaluate the effect of bar movement on cross-sectional topography, we calculate the value of $\mathrm{N}=\ell_{2} / \ell_{1}$ by defining $\beta$ and $\theta$ (Figure 4).
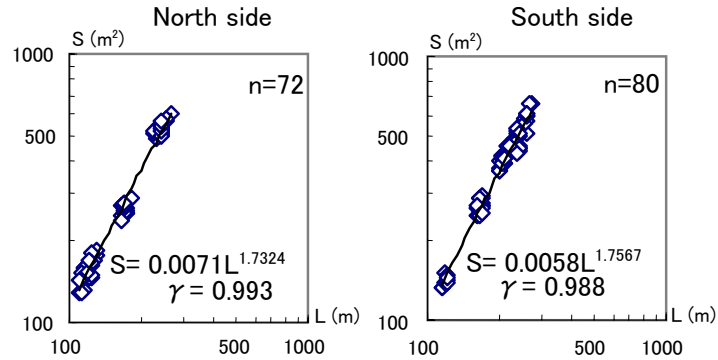

(a) Ishikari Beach

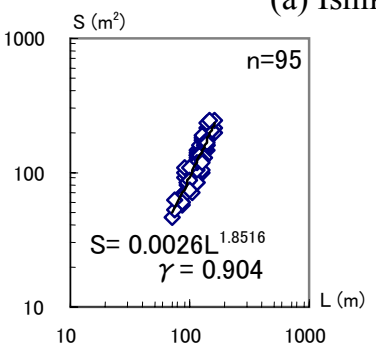

(b) Tomakomai Beach

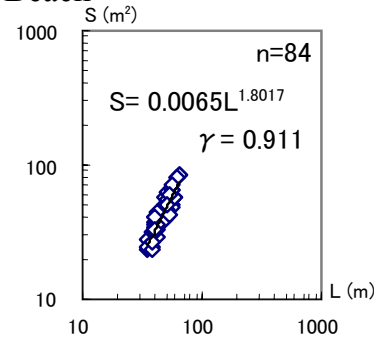

(c) Sarukotsu Beach

Figure 5: $\quad$ Relationship between area $(\mathrm{S})$ and circumference $(\mathrm{L})(\gamma$ : correlation coefficient, n: number of cross sections).

Table 3: $\quad$ Fractal dimension results for the beaches examined.

\begin{tabular}{|c|c|c|c|}
\hline Beach & $\begin{array}{c}\text { Number of } \\
\text { cross } \\
\text { sections }\end{array}$ & Fractal Dimension (D) & Correlation coefficient $(\gamma)$ \\
\hline Ishikari (All) & 152 & 1.152 & 0.991 \\
\hline Ishikari (North side) & 72 & 1.154 & 0.993 \\
\hline Ishikari (South side) & 80 & 1.138 & 0.988 \\
\hline Tomakomai & 95 & 1.080 & 0.904 \\
\hline Sarukotsu & 84 & 1.110 & 0.911 \\
\hline
\end{tabular}

$$
\begin{aligned}
& h_{b}=\ell_{1} \tan \beta \\
& h^{\prime}=\ell_{2} \tan \theta \\
& h_{c}=h_{b}+h^{\prime}
\end{aligned}
$$

Using above expression, $\mathrm{N}$ can be derived as 


$$
N=\frac{\ell_{2}}{\ell_{1}}=\frac{\ell \tan \beta-h_{c}}{h_{c}-\ell \tan \theta}
$$

with equation (4) being used where $\tan \beta>h_{c} / \ell$ and $\tan \theta<h_{c} / \ell$.

Figure 6 shows the histogram for $\mathrm{N}=\ell_{2} / \ell_{1}$ at the Ishikari (north and south sides), Tomakomai, and Sarukotsu Beaches. Table 4 shows the median, average, and standard deviation of $\mathrm{N}$. Furthermore, Table 5 shows the values of $\tan \beta$ and $\tan \theta$. In addition, if the data have not satisfied the condition $\tan \beta>h_{c} / \ell$ and $\tan \theta<h_{c} / \ell$, we have not used these data. Therefore, the number of data in Figure 6 disagrees with those in Table 1.

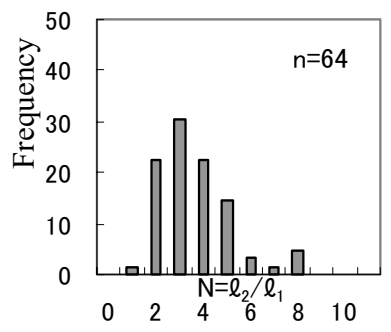

(a) Ishikari Beach (South) (\%)

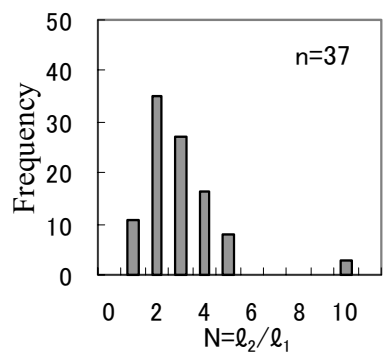

(c) Tomakomai Beach

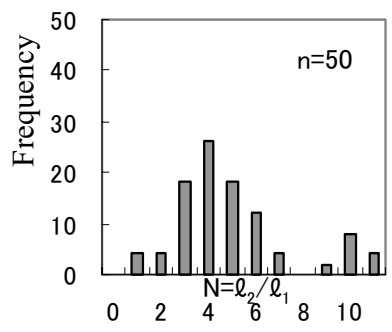

(b) Ishikari Beach (North) (\%)

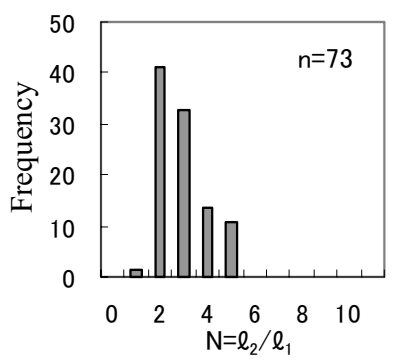

(d) Sarukotsu Beach

Figure 6: Distribution frequency of $\mathrm{N}=\ell_{2} / \ell_{1}$.

Based on the findings presented in Figure 6, and Tables 4 and 5, we can discuss the relationship between beach cross-sectional topography and the magnitudes of $\tan \beta$ and $\tan \theta$.

As shown in Table 4, a relatively higher standard deviation for $\mathrm{N}$ was observed on the north side of Ishikari Beach compared to the other beaches sampled. It is assumed that the changes in the topography of the coast observed on the north side of Ishikari Beach has occurred as a result of considerable alongshore transport of sediment. As shown in Table 5, the values of $\tan \beta$ and $\tan \theta$ at Ishikari beach is approximately $1 / 4$ times and $1 / 2$ that of Sarukotsu Beach. Similarly, because sand-grain size at Ishikari beach is smaller than that 
observed at Tomakomai and Sarukotsu beaches, $\tan \theta$ on Tomakomai Beach is approximately 4/5 times of that on Sarukotsu Beach. As shown in Figure 6 for the north and the south sides of Ishikari beach, the same trend is observed where $1 \leq \mathrm{N} \leq 7$. Also, the values of $\tan \beta$ and $\tan \theta$ on the north and the south sides of Ishikari Beach are nearly equal (Table. 5). Consequently, it is inferred that the fractal dimensions on the north and south sides of Ishikari Beach are also approximately equal. The value of the fractal dimension therefore appears to be dependent on bar formation.

\subsection{Effect of foreshore slope on fractal dimension}

We also examine the effect of the foreshore slope on the fractal dimension. Here, we define the foreshore slope $\alpha$ as shown in Figure 4.

In order to determine the effect of foreshore slope $\tan \alpha$ on the fractal dimension, the data for $\tan \alpha$ (95 cross sections) are arranged as a function of $\tan \beta$ and the bar crest depth $h_{\mathrm{b}}$ as shown in Figure 7. As shown in Figure 7, the value of $\tan \beta$ increases as the value of $\tan \alpha$ decreases, and bar crest height $h_{b}$ increases as $\tan \beta$ increases. It therefore appears that foreshore slope $\alpha$ is affected by bar formation.

\section{Concluding remarks}

We investigated the topographical characteristics of the Ishikari, Tomakomai, and Sarukotsu Beaches facing the different oceans by conducting beach surveys. We attempted to elucidate various characteristics of beach topography at the beaches of Ishikari, Tomakomai, and Sarukotsu using fractal theory. The results of our research can be summarized as follows:

Table 4: $\quad$ Values for $N=\ell_{2} / \ell_{1}$.

\begin{tabular}{|c|c|c|c|}
\hline Beach & Median & Average & Standard deviation \\
\hline Ishikari (North) & 3.823 & 4.651 & 3.117 \\
\hline Ishikari (South) & 2.870 & 3.182 & 1.517 \\
\hline Tomakomai & 2.104 & 2.427 & 1.667 \\
\hline Sarukotsu & 2.121 & 2.417 & 1.006 \\
\hline
\end{tabular}

Table 5: $\quad$ Comparison of $\tan \beta, \tan \theta$, and seafloor slope.

\begin{tabular}{|c|c|c|c|c|}
\hline Beach & Beach characteristics & $\tan \beta$ & $\tan \theta$ & Seafloor slope \\
\hline $\begin{array}{c}\text { Ishikari } \\
\text { (North) }\end{array}$ & Sedimented beach & $1 / 88$ & $1 / 119$ & - \\
\hline $\begin{array}{c}\text { Ishikari } \\
\text { (South) }\end{array}$ & Eroded beach & $1 / 88$ & $1 / 115$ & $1 / 122$ \\
\hline Tomakomai & Equilibrated beach & $1 / 94$ & $1 / 76$ & $1 / 142$ \\
\hline Sarukotsu & Beach disturbed by drift ice & $1 / 22$ & $1 / 67$ & $1 / 141$ \\
\hline
\end{tabular}




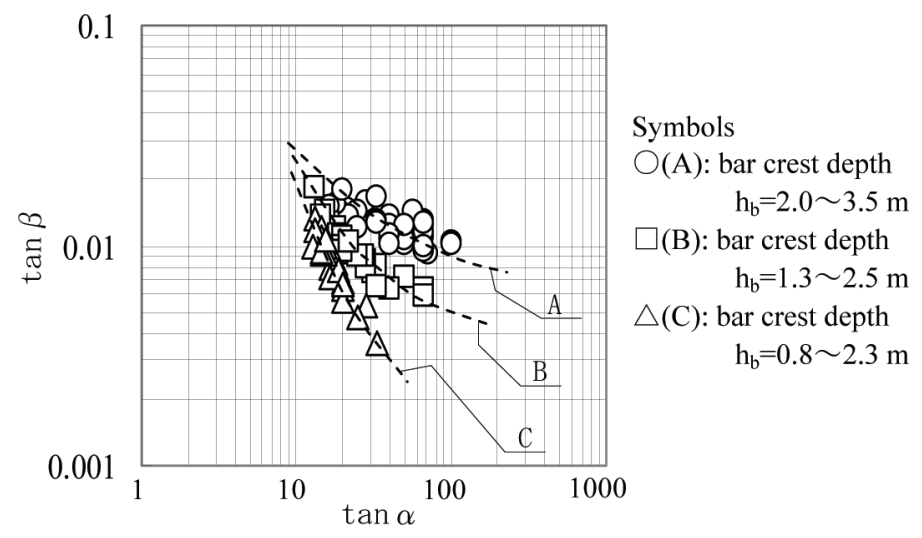

Figure 7: Relationship between $\tan \alpha$ and $\tan \beta$.

1. For Tomakomai Beaches facing the Pacific Ocean, littoral drift occurs by suspension, transition, and traction. The littoral drift conditions at Ishikari Beach, facing the Japan Sea, are similar to those observed at Sarukotsu Beach, which faces the Ohotsuku Sea.

2. The foreshore slope at Sarukotsu Beach was greater than those of the other beaches analyzed as it has frequently been eroded by drift ice.

3. The range in the fractal dimension value for Ishikari, Tomakomai, and Sarukotsu Beaches was 1.08 1.15.

4. Despite the differences between the beach to the north and south of the harbor on Ishikari Beaches, since the same fractal dimension value was obtained, it appears that the beach topography of this area exhibits selfsimilarity provided both stretches of beach are subjected to the same wave conditions.

5. The magnitude of the fractal dimension was affected by the foreshore slope, the position of the bar, and the bar crest depth.

6. Utilization of fractal dimension to demonstrate the complex attributes of cross-sectional coastal topography was found to be useful.

\section{References}

[1] Horikawa, S. et al. A few considerations on shoreline changes, Proceedings of $22^{\text {nd }}$ Annual Conference on Coastal Engineering, Vol. 22, pp. 329-334, 1975 (in Japanese).

[2] Shibayama, T. and Horikawa, K., A numerical model for two-dimensional beach transformation, Proceedings of JSCE, Vol. 357, 1985 (in Japanese).

[3] Iwagaki, Y., Modern Costal Engineering, Morikita publishing company, 1987 (in Japanese).

[4] http://en.wikipedia.org/wiki/Fractal

[5] Kubo, M. and Tomaki, S., On the stable point of cross-sectional topography of coastlines, $28^{\text {th }}$ Annual Conference on Coastal Engineering, Vol.28, pp. 247-250, 1981 (in Japanese). 